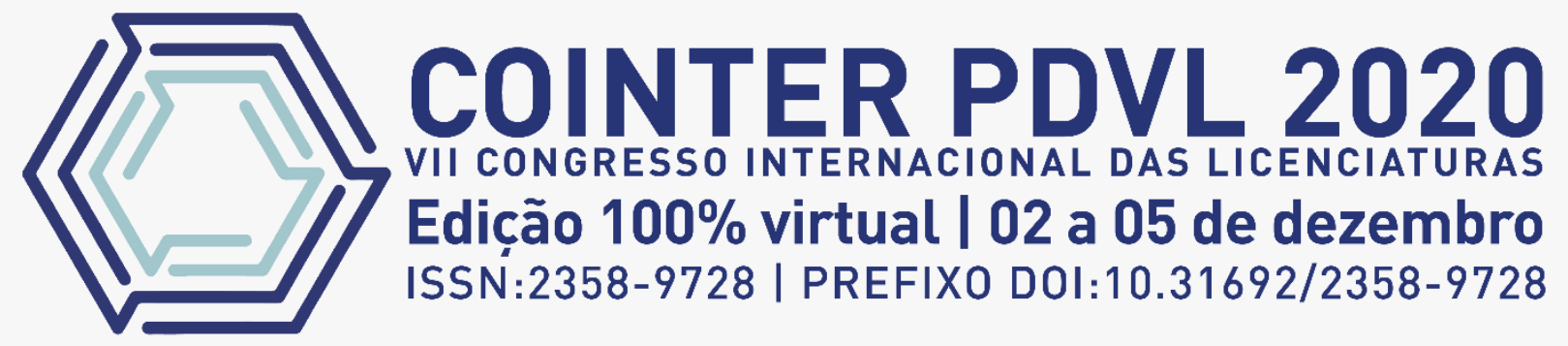

\title{
OFICINAS DE LIBRAS COMO L2 PARA ALUNOS OUVINTES: POSSIBILIDADES DE INCLUSÃO
}

\author{
TALLERES DE LIBRAS COMO L2 PARA ESTUDIANTES ESCUCHA: \\ POSIBILIDADES DE INCLUSIÓN
}

\section{LIBRAS WORKSHOPS AS L2 FOR LISTENING STUDENTS: POSSIBILITIES OF INCLUSION}

\author{
Apresentação: Comunicação Oral
}

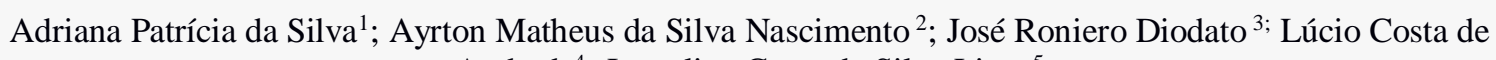
Andrade $^{4}$; Jaqueline Costa da Silva Lima ${ }^{5}$

DOI: https://doi.org/10.31692/2358-9728.VIICOINTERPDVL.0337

\begin{abstract}
RESUMO
Sabemos que no Brasil a Libras é regulamentada, entretanto como pode-se de modo mais eficiente promover a inclusão do individuo surdo em nosso país? Porque em nossas escolas não há o ensino da Libras desde a primeira infância para todos os alunos? Estas são questões que se resolvidas mudariam a vida dos sujeitos surdos e promoveria uma inclusão real, inclusão esta que não necessitaria de tantos requisitos para acontecer, pois fluiria naturalmente em todo indivíduo brasileiro. Desse modo, o objetivo do presente estudo foi realizar uma revisão da literatura a fim de identificar possiblidades de inclusão através de oficinas de Libras como segunda língua (L2) para alunos ouvintes. Foi feito um levantamento da literatura em setembro de 2020, na base de dados Google Acadêmico. Os descritores utilizados foram os seguintes: "Inclusão" AND "Oficinas de Libras" AND "Ensino de Libras para ouvintes" nesta base de dados. Foram selecionados 02 artigos sendo incluídos segundo os critérios de elegibilidade. Os critérios de inclusão foram: artigos no idioma português, nos últimos cinco anos, envolvendo o conhecimento sobre oficinas de libras como L2 para alunos ouvintes: Possibilidades de inclusão. Os critérios de exclusão foram artigos de revisão de literatura. 100\% dos artigos selecionados fizeram menção de que o ensino da libras para os alunos ouvintes é fundamental para a real inclusão do sujeito surdo na escola bem como, na sociedade. Nesse sentido, podemos observar que existem possibilidades sim de inclusão através do ensino da Língua Brasileira de Sinais (Libras) nas escolas públicas, visto que quando tratamos de inclusão apenas pensamos nos alunos com deficiência, mas existe um mundo a ser acessado pelos ouvintes.
\end{abstract}

${ }^{1}$ Graduanda em Letras Libras, Centro Universitário Leonardo Da Vinci/UNIASSELVI, dry.patricia@hotmail.com

${ }^{2}$ Mestrando em Educação em Ciências e Matemática - PPGECM, pela Universidade Federal de Pernambuco (UFPE/CAA), Especialista em Ensino de Química e Graduado em Licenciatura em Química pelo Instituto Federal de Pernambuco (IFPE - Campus Vitória), ayrton.nascimento@ufpe.br

${ }_{3}^{3}$ Pedagogo, Graduando em Letras Libras, Universidade Federal de Pernambuco/UFPE, roniero.diodato@ufpe.br ${ }^{4}$ Pedagogo, Graduando em Letras Libras, Universidade Federal da Paraíba/UFPB, lucio.costa@academico.ufpb.br

5 Pedagoga, Graduanda em Letras Libras, pelo Centro Universitário Leonardo Da Vinci/UNIASSELVI, Especialista em Psicopedagogia Clínica pela UNIFACOL e Proficiência em Tradução e Interpretação da Libras pela ALPHA, jaqueline.costal@ufpe.br 
Palavras-Chave: Inclusão, Oficinas de Libras e Ensino de Libras para ouvintes.

\section{RESUMEN}

Sabemos que en Brasil los Libra están regulados, sin embargo, ¿cómo podemos promover de manera más eficiente la inclusión de las personas sordas en nuestro país? ¿Por qué no se enseña Libra desde la primera infancia para todos los estudiantes de nuestras escuelas? Son cuestiones que, de resolverse, cambiarían la vida de las personas sordas y promoverían la inclusión real, una inclusión que no necesitaría tantos requisitos para suceder, ya que fluiría naturalmente en cada individuo brasileño. Así, el objetivo del presente estudio fue realizar una revisión de la literatura con el fin de identificar posibilidades de inclusión a través de talleres de Libras como segunda lengua (L2) para estudiantes oyentes. Se realizó una encuesta bibliográfica en septiembre de 2020, en la base de datos de Google Scholar. Los descriptores utilizados fueron los siguientes: "Inclusión" Y "Talleres de Libras" Y "Enseñanza de Libras a los oyentes" en esta base de datos. Se seleccionaron e incluyeron 02 artículos de acuerdo con los criterios de elegibilidad. Los criterios de inclusión fueron: artículos en lengua portuguesa, en los últimos cinco años, que involucren conocimientos sobre talleres L2 como L2 para estudiantes oyentes: Posibilidades de inclusión. Los criterios de exclusión fueron artículos de revisión de la literatura. El 100\% de los artículos seleccionados mencionó que la enseñanza de libras a estudiantes oyentes es fundamental para la inclusión real del sujeto sordo en la escuela y en la sociedad. En este sentido, podemos observar que existen posibilidades de inclusión a través de la enseñanza de la Lengua de Signos Brasileña (Libras) en las escuelas públicas, ya que cuando nos ocupamos de la inclusión solo pensamos en los estudiantes con discapacidad, pero hay un mundo al que pueden acceder los oyentes.

Palabras Clave: Inclusión, Talleres Libras y Enseñanza Libras para oyentes.

\section{ABSTRACT}

We know that in Brazil Libras are regulated, however how can we more efficiently promote the inclusion of the deaf individual in our country? Why is there no teaching of Libras since early childhood for all students in our schools? These are issues that, if resolved, would change the lives of deaf individuals and promote real inclusion, an inclusion that would not need so many requirements to happen, as it would flow naturally in every Brazilian individual. Thus, the objective of the present study was to carry out a literature review in order to identify possibilities for inclusion through Libras as a second language (L2) workshops for hearing students. A literature survey was conducted in September 2020, in the Google Scholar database. The descriptors used were the following: "Inclusion" AND "Libras Workshops" AND "Libras Teaching to listeners" in this database. 02 articles were selected and included according to the eligibility criteria. The inclusion criteria were: articles in the Portuguese language, in the last five years, involving knowledge about L2 workshops like L2 for hearing students: Possibilities for inclusion. The exclusion criteria were literature review articles. $100 \%$ of the selected articles mentioned that teaching libras to hearing students is fundamental for the real inclusion of the deaf subject in school as well as in society. In this sense, we can observe that there are possibilities of inclusion through the teaching of the Brazilian Sign Language (Libras) in public schools, since when we deal with inclusion we only think about students with disabilities, but there is a world to be accessed by listeners.

Keywords: Inclusion, Libras Workshops and Libras Teaching for listeners.

\section{INTRODUÇÃO}

Libras é a Língua Brasileira de Sinais, reconhecida através da Lei 10.436/2002 como meio de comunicação e expressão e regulamentada pelo decreto 5.626/2005. É a língua natural/materna dos surdos brasileiros e sua modalidade é visual-espacial, sendo possível a inclusão do sujeito surdo através da utilização desta língua.

Nesse sentido, Inclusão é definida como o ato de acolher pessoas independentemente 
de sua cor, etnia, religião, condições físicas e/ou psicológicas, sem exceções, principalmente quando tratamos sobre a inclusão no âmbito educacional.

Assim sendo a escola comum torna-se inclusiva quando acolhe as diferenças dos alunos mediante o processo educacional buscando dessa forma a participação efetiva, bem como, a evolução de todos os educandos, sempre inovando em suas práticas pedagógicas, entretanto sabemos que esta não é uma tarefa fácil, pois requer a adoção de medidas e novas práticas para então gerar mudanças que atravessarão os muros da escola (FRANCO; SCHUTZ, 2019).

Dessa forma podemos utilizar as oficinas de Libras que são projetos voltados para a formação de pessoas com o objetivo de torna-las bilíngues e de promover a interatividade entre surdos e ouvintes, contribuindo para o crescimento pessoal e profissional.

Além disso, o ensino de Libras para ouvintes pode ser definido como o ensino de Libras como uma segunda língua (L2), visto que os sujeitos ouvintes brasileiros tem o português como primeira língua (L1) desse modo, a aprendizagem de duas línguas, de forma simultânea, é positiva para o desenvolvimento da criança.

O processo de aquisição da segunda língua ocorre de maneira distinta entre crianças e adultos. Entre alguns motivos, está o fato de o adulto já ter conhecimentos prévios da língua e a criança ter a tendência de não recear o erro ao aprender a segunda língua. Behaviorismo - O contexto determina o desenvolvimento (BARBOSA; LACERDA, 2019).

No que diz respeito ao contexto histórico do ensino da Língua de Sinais, seu ensino como segunda língua foi fortemente desenvolvido no contexto americano, da ASL. No Brasil ainda possuímos poucas referências sobre este tema. Consideramos L1 como língua materna adquirida no contexto familiar do sujeito. L2 é aquela diferente na língua materna, aprendida em contextos formais ou não formais de ensino e, língua estrangeira como a língua do outro, aquela que é desconhecida (BARBOSA; LACERDA, 2019).

Nesse sentido, sabemos que no Brasil a Libras é regulamentada, entretanto como pode-se de modo mais eficiente promover a inclusão do individuo surdo em nosso país? Porque em nossas escolas não há o ensino da Libras desde a primeira infância para todos os alunos? Estas são questões que se resolvidas mudariam a vida dos sujeitos surdos e promoveria uma inclusão real, inclusão esta que não necessitaria de tantos requisitos para acontecer, pois fluiria naturalmente em todo indivíduo brasileiro.

Por isso o objetivo do presente estudo foi realizar uma revisão da literatura a fim de identificar possiblidades de inclusão através de oficinas de Libras como segunda língua (L2) para alunos ouvintes. 


\section{FUNDAMENTAÇÃO TEÓRICA}

A educação inclusiva está no cotidiano educacional abrangendo todos os indivíduos presentes neste contexto. Assim,

A educação inclusiva constitui um paradigma educacional fundamentado na concepção de direitos humanos, que conjuga igualdade e diferença como valores indissociáveis, e que avança em relação à ideia de equidade formal ao contextualizar as circunstâncias históricas da produção da exclusão dentro e fora da escola (BRASIL, 2008).

Nesse sentido, temos a Língua Brasileira de Sinais (Libras) que é reconhecida e regulamentada como meio de comunicação e expressão através da Lei 10.436/2002. Sendo assim esta não está restrita apenas a comunidade surda de nosso país, mas pode ser utilizada e seu uso incentivado por qualquer individuo.

A maioria dos indivíduos surdos nasce em famílias ouvintes, estes muitas vezes só entram em contato com a Libras na escola tardiamente, visto que a aquisição da linguagem por qualquer individuo ouvinte se dá desde o nascimento por meio de estímulos /inputs externos, com os surdos não deveria ser diferente pois os mesmos são perfeitamente capazes de receber esses inputs que devem ser visuais.

[...] para que as crianças surdas tenham uma efetiva aquisição da Libras e um desenvolvimento linguístico e cognitivo que lhes possibilite uma escolarização de qualidade, a educação bilíngue para surdos em turmas específicas ou em escolas de surdos, na educação infantil e anos iniciais, segundo muitas pesquisas apontam, parece ser mais indicada (THOMA, 2011, p. 139).

Entretanto, os surdos até conseguem receber uma educação bilíngue para se comunicar, mas de que adianta se nas escolas públicas do nosso país os ouvintes não recebem essa educação? Se todos aprendessem Libras desde a infância não enfrentaríamos tantas barreiras comunicacionais. Nesse sentido, as oficinas de Libras são uma possibilidade de inclusão dos alunos ouvintes na comunidade surda.

Dito isso, outro fator importante, é a formação da família em um contexto bilíngue, para que os surdos desde a primeira infância recebam os estímulos necessários, para seu pleno desenvolvimento linguístico. Com isso a surdez pode ser compreendida "como um território de lutas, um espaço de conflitos de identidades, onde os elementos culturais circulam pelas fissuras e rachaduras dessa comunidade, conformando um labirinto de significados" (KLEIN, 2009).

Nesse sentido, onde e quando o ensino de Libras é obrigatório? O Decreto ${ }^{\circ} 5.626$, de 2005, que regulamenta a Lei $n^{\mathbf{o}} 10.436 / 2002$, demarca a obrigatoriedade da disciplina de Libras no curso de Fonoaudiologia e em cursos de formação de professores, nível médio e 
superior. Nos demais cursos, a disciplina de Libras fica como optativa. A inclusão da disciplina de Libras é abordada no segundo capítulo do decreto, intitulado DA INCLUSÃO DA LIBRAS COMO DISCIPLINA CURRICULAR, e dispõe que:

\begin{abstract}
Art. $3^{\circ}$ A Libras deve ser inserida como disciplina curricular obrigatória nos cursos de formação de professores para o exercício do magistério, em nível médio e superior, e nos cursos de Fonoaudiologia, de instituições de ensino, públicas e privadas, do sistema federal de ensino e dos sistemas de ensino dos Estados, do Distrito Federal e dos Municípios.

$\S 1$ Todos os cursos de licenciatura, nas diferentes áreas do conhecimento, o curso normal de nível médio, o curso normal superior, o curso de Pedagogia e o curso de Educação Especial são considerados cursos de formação de professores e profissionais da educação para o exercício do magistério.

$\S 20$ A Libras constituir-se-á em disciplina curricular optativa nos demais cursos de educação superior e na educação profissional, a partir de um ano da publicação deste Decreto.
\end{abstract}

De acordo com o exposto, a obrigatoriedade da disciplina de Libras incide nos cursos de formação de professores e no curso de Fonoaudiologia. A inclusão da disciplina nos currículos dos cursos, de acordo com o art. $9^{\circ}$ do decreto, deveria ter o alcance de $100 \%$ dos cursos, em dez anos, a partir da data da sua publicação.

Cabe ressaltar que o Decreto $n^{\circ} 5.626 / 2005$ não faz referência quanto às diretrizes desta disciplina, ou seja, sua carga horária, referências, sistematização da proposta da disciplina. Tampouco houve publicação de diretrizes ou orientações sobre a disciplina de Libras, desde a publicação do decreto em 2005.

Para pensarmos o ensino de Língua de Sinais como segunda língua é preciso considerar o perfil do estudante, ou seja, quem é este sujeito? Quais as motivações que o levam a aprender a Libras? Qual é o seu contexto de aprendizagem? No Brasil, poucos estudos se dedicam ao ensino da Língua Brasileira de Sinais como L2.

Uma das pesquisadoras que se lançou sobre esta temática foi a professora Audrei Gesser, que desenvolveu pesquisas sobre a aprendizagem da Libras por alunos ouvintes. Ao analisar vários contextos de ensino de Libras, o primeiro apontamento da autora é a necessidade que eles possuem, ao ter contato com a Libras, de "legitimar a língua de sinais enquanto língua" (GESSER, 2012).

Nesse sentido, refletir e organizar o ensino de Libras para ouvintes requer uma leitura sobre qual é a compreensão dos estudantes com relação ao status linguístico da Libras. Não é possível desconsiderar também que os estudantes estão inseridos em um contexto majoritário ouvinte e que, portanto, serão afetados pelas concepções da língua de sinais que perpassam o senso comum. Segundo Barbosa, 2019:

A inserção da disciplina de Libras, seja como disciplina obrigatória ou optativa, possibilitou um maior (re)conhecimento da Língua de Sinais. Além disso, as 


\section{OFICINAS DE LIBRAS COMO L2 PARA ALUNOS OUVINTES}

próprias instituições passaram a ofertar cursos de extensão para ensino de Libras, o que possibilitou uma maior difusão desta língua na sociedade. Nesse sentido, as disciplinas, mas, principalmente, os cursos de Libras, recebem um público muito variado de estudantes. Além disso, os interesses que os motivam são bastante variados, conforme sinalizou Gesser. E como pensar o ensino de Libras diante dessa diversidade de estudantes e de interesses? Como pensar um ensino de Libras que dê conta do estudante que pretende trabalhar como intérprete e daquele que quer apenas se comunicar com um familiar surdo?

Podemos ir além e questionar, como pensar na criança ouvinte que se torna um adulto e nunca ouviu se quer falar sobre a Libras? Como mudar a realidade de um país que persiste em tratar seus filhos como estrangeiros? Para mudarmos essa realidade temos que mudar as politicas públicas e possibilitar o ensino de Libras desde a infância nas escolas públicas do nosso país.

Além disso, no contexto do ensino superior, não há uma regularidade quanto ao ensino da disciplina de Libras, sendo este um fator de impacto nas praticas de ensino na realidade das escolas brasileiras, ficando o ensino desta discuplina a merce do bon senso de cada instituição. Para isso o Decreto no 5.626/2005 afirma:

Art. $4^{\circ} \mathrm{A}$ formação de docentes para o ensino de Libras nas séries finais do ensino fundamental, no ensino médio e na educação superior deve ser realizada em nível superior, em curso de graduação de licenciatura plena em Letras: Libras ou em Letras: Libras/Língua Portuguesa como segunda língua.

Parágrafo único. As pessoas surdas terão prioridade nos cursos de formação previstos no caput.

Art. $5^{\circ} \mathrm{A}$ formação de docentes para o ensino de Libras na educação infantil e nos anos iniciais do ensino fundamental deve ser realizada em curso de Pedagogia ou curso normal superior, em que Libras e Língua Portuguesa escrita tenham constituído línguas de instrução, viabilizando a formação bilíngue.

$\S 1^{\circ}$ Admite-se como formação mínima de docentes para o ensino de Libras na educação infantil e nos anos iniciais do ensino fundamental, a formação ofertada em nível médio na modalidade normal, que viabilizar a formação bilíngue, referida no caput.

$\S 2^{\circ}$ As pessoas surdas terão prioridade nos cursos de formação previstos no caput.

Art. $6^{\circ}$ A formação de instrutor de Libras, em nível médio, deve ser realizada por meio de:

I - cursos de educação profissional;

II - cursos de formação continuada promovidos por instituições de ensino superior; e

III - cursos de formação continuada promovidos por instituições credenciadas por secretarias de educação.

$\S 1^{\circ}$ A formação do instrutor de Libras pode ser realizada também por organizações da sociedade civil representativa da comunidade surda, desde que o certificado seja convalidado por pelo menos uma das instituições referidas nos incisos II e III.

$\S 2^{\circ}$ As pessoas surdas terão prioridade nos cursos de formação previstos no caput.

Quando tratamos do ensino de Libras como L2, pode-se atrair um público bastante diverso e com motivaçoes variadas, podendo ser por um anseio de ser intérprete, lecionar a língua em questão, para comunicar-se com amigos ou familiares surdos. Nesse sentido devese escolher uma estrategia ou várias de ensino que atenda a necessidade do público em questão. 


\section{METODOLOGIA}

Foi feito um levantamento da literatura em setembro de 2020, na base de dados Google Acadêmico. Os descritores utilizados foram os seguintes: "Libras" AND "Inclusão" AND "Oficinas de Libras" AND "Ensino de Libras para ouvintes" nesta base de dados. Foram selecionados 03 artigos sendo incluídos segundo os critérios de elegibilidade conforme a Figura 1. Os critérios de inclusão foram: artigos no idioma português, nos últimos cinco anos, envolvendo o conhecimento sobre oficinas de libras como L2 para alunos ouvintes: Possibilidades de inclusão. Os critérios de exclusão foram artigos de revisão de literatura.

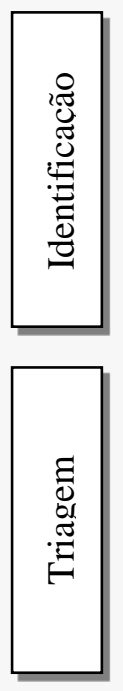

Artigos encontrados na base de dados Google Acadêmico ( $\mathrm{n}=1190)$
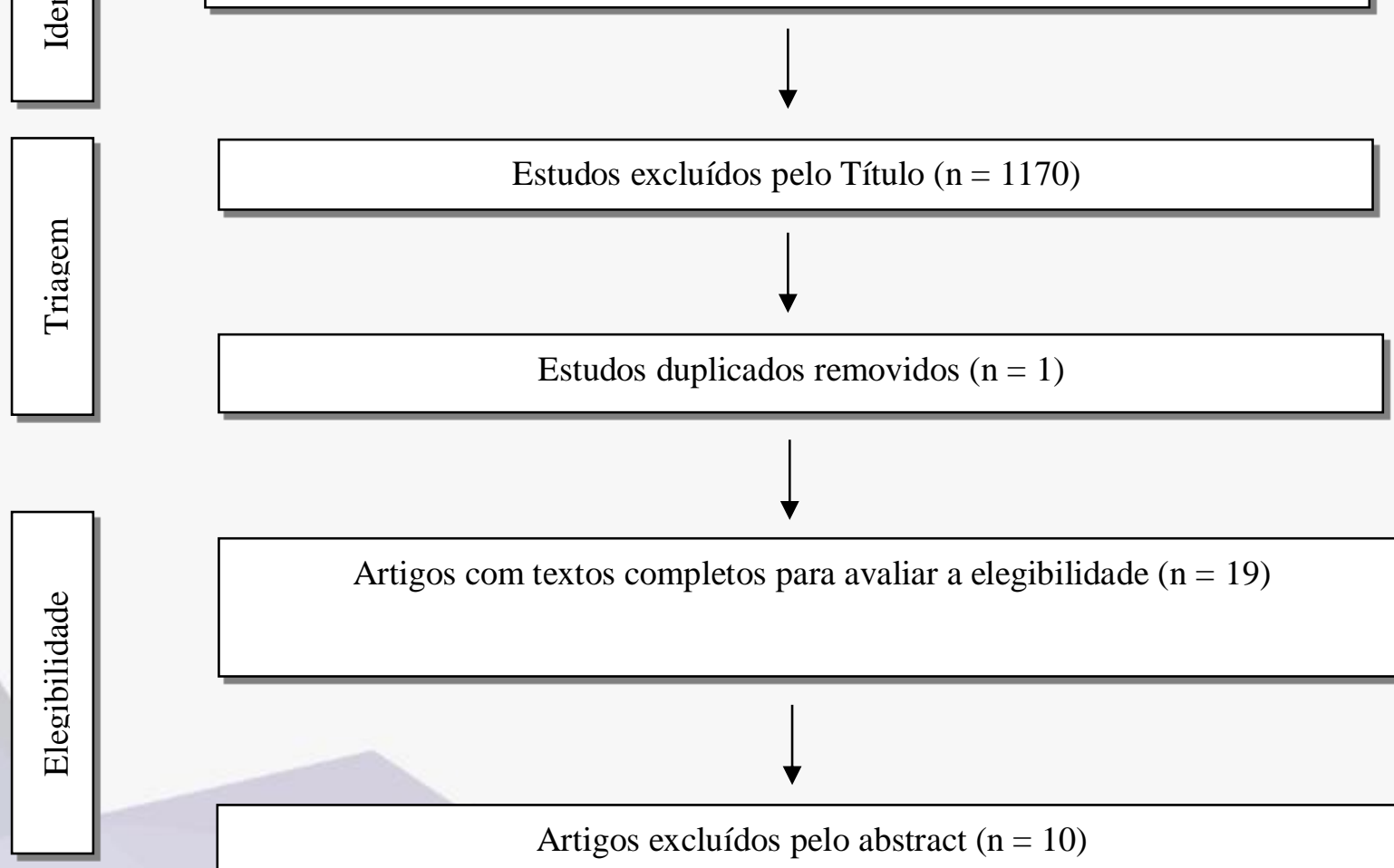

Artigos com textos completos para avaliar a elegibilidade $(n=19)$

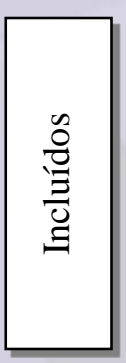

Artigos excluídos a partir da leitura do texto complete $(\mathrm{n}=06)$

Artigos excluídos pelo abstract $(\mathrm{n}=10)$

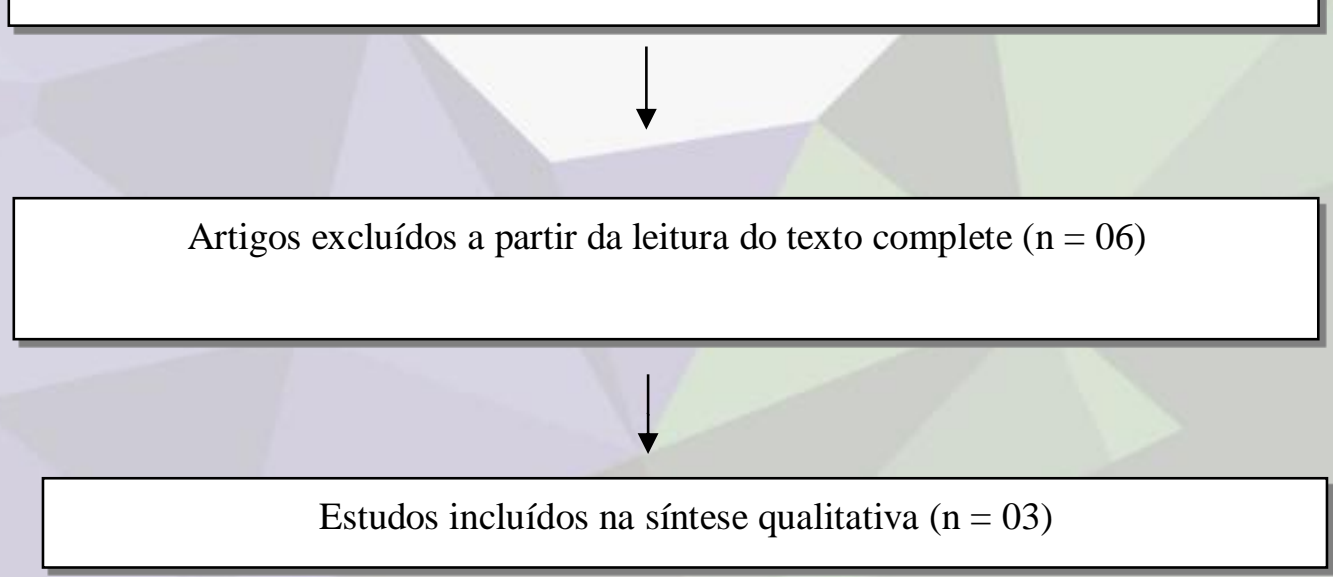

FIGURA 01: Fluxograma e critérios de seleção e inclusão dos Artigos 


\section{RESULTADOS E DISCUSSÃO}

Os resultados do presente estudo encontram-se no na Tabela 01.

Tabela 1 - Demonstrativo dos artigos que integram a Revisão Integrativa

\begin{tabular}{|c|c|c|c|c|c|c|}
\hline$\# \mathbf{N}$ & Data & Título & Autores & Periódico & Objetivos & Resultados \\
\hline 1 & 2017 & $\begin{array}{l}\text { Os diferentes } \\
\text { caminhos para } \\
\text { Uma educação } \\
\text { bilíngue } \\
\text { (libras/português) } \\
\text { na região sul do } \\
\text { brasil }\end{array}$ & $\begin{array}{l}\text { Neiva A. } \\
\text { Albres }\end{array}$ & $\begin{array}{l}\text { Revista Artes } \\
\text { de Educar }\end{array}$ & $\begin{array}{l}\text { Descrever os } \\
\text { espaços } \\
\text { Disponibilizados } \\
\text { para a educação } \\
\text { de surdos na } \\
\text { região sul do } \\
\text { Brasil. }\end{array}$ & $\begin{array}{l}\text { Constatou-se que em } \\
\text { todos os estados há } \\
\text { Escolas inclusivas } \\
\text { organizando-se para } \\
\text { desenvolver uma } \\
\text { educação bilíngue. }\end{array}$ \\
\hline 2 & 2017 & $\begin{array}{l}\text { O trabalho com } \\
\text { narrativas } \\
\text { audiovisuais no } \\
\text { ensino de Libras } \\
\text { como L2 para } \\
\text { ouvintes }\end{array}$ & $\begin{array}{l}\text { Aryane } \\
\text { Nogueira; } \\
\text { Janaina } \\
\text { Cabello }\end{array}$ & $\begin{array}{l}\text { Revista } \\
\text { Leitura V.1 } \\
\mathrm{n}^{0} 57\end{array}$ & $\begin{array}{l}\text { Relatar } \\
\text { experiencias } \\
\text { ensino de Libras } \\
\text { como L2 para } \\
\text { alunos ouvintes, } \\
\text { utilizando a } \\
\text { elaboração de } \\
\text { narrativas }\end{array}$ & $\begin{array}{l}\text { O recurso de } \\
\text { elaboração de } \\
\text { narrativas possibilitou } \\
\text { o envolvimento dos } \\
\text { alunos na construção } \\
\text { textual em Libras, o } \\
\text { que mobilizou os } \\
\text { conhecimentos } \\
\text { linguísticos, políticos } \\
\text { e sociais } \\
\text { desenvolvidos ao } \\
\text { longo das aulas. }\end{array}$ \\
\hline 3 & 2016 & Oficina de Libras & $\begin{array}{l}\text { Natalia } \\
\text { Amarilho } \\
\text { Pereira }\end{array}$ & $\begin{array}{l}4^{\circ} \text { Semex - } \\
\text { Seminário de } \\
\text { Extensão }\end{array}$ & $\begin{array}{l}\text { Oportunizar o } \\
\text { acesso a Libras } \\
\text { para a construção } \\
\text { de uma sociedade } \\
\text { mais igualitária e } \\
\text { de respeito ao } \\
\text { próximo. }\end{array}$ & $\begin{array}{l}\text { Verificou-se que 94\% } \\
\text { dos participantes } \\
\text { concordaram } \\
\text { plenamente que o } \\
\text { Projeto forneceu } \\
\text { conhecimento } \\
\text { suficiente sobre a } \\
\text { Libras.. }\end{array}$ \\
\hline
\end{tabular}

Fonte: Própria (2020)

O objetivo do presente estudo é identificar possiblidades de inclusão através de oficinas de Libras como segunda língua (L2) para alunos ouvintes.

Nesse sentido Albres (2017), realizou uma pesquisa procurando descrever os espaços disponíveis para a educação de surdos na região sul do Brasil, identificando que esta educação acontece em salas mistas, ou seja, no contato entre surdos e ouvintes, constatando a urgência do ensino de Libras também para os alunos ouvintes. Desse modo, a autora destaca sobre o discurso da educação bilíngue, que na prática não são viabilizadas pelas Secretarias de Educação, pois não compensam devido o baixo número de estudantes surdos.

Assim, pode-se constatar que em todos os estados há escolas inclusivas organizandose para desenvolver uma educação bilíngue. 
Verificamos que não há uma equidade de oferta dos diferentes espaços para realização da educação de surdos, ou seja, não há no mesmo estado, muito menos em uma mesma cidade o direito de escolha pelo surdo onde estudar. Quando tratamos de escola pública, garante-se à educação na escola comum como direito fundamental de todos, ou seja, a escola comum é vista como um espaço onde todos devem estar juntos e no qual as diferenças devem ser respeitadas e valorizadas. Mas, esse respeito perpassa pela aceitação e valorização da língua, do atendimento às necessidades específicas educacionais, que com a colocação de intérprete de libras, por vezes, sem formação e aulas de libras em tempo diverso não se configuram como uma real educação bilíngue (ALBRES, 2017).

Além disso, quando trata-se de escolas públicas garante-se a educação como direito fundamental, assim é necessário haver equidade no ensino e na comunicação, pois a língua de sinais está presente no cotidiano escolar e é a realidade de surdos e ouvintes lidar com as barreiras comunicacionais.

Com isso, Albres (2017) encerra sua pesquisa reafirmando

A necessidade de respeito aos interesses dos surdos como minoria linguística, de uma visão cultural, de referências multi/interculturais do que se seguir cegamente o discurso da inclusão e poder se repensar os espaços escolares para além da sala de aula em que estejam corpos surdos e ouvintes sem que haja uma comunicação, interação e aprendizagem efetivamente.

Nesse sentido, Nogueira e Cabello (2017), apresentaram um artigo com seus relatos de experiências referente ao ensino de Libras como L2 para alunos ouvintes, tendo como proposta pedagógica, fundamentada em uma abordagem de ensino de língua comunicativa, a elaboração de narrativas audiovisuais pelos alunos participantes de cursos de Libras.

Considerando que os estudos sobre metodologias para o ensino de língua de sinais ainda são em pequeno número, a intenção foi de contribuir para a área de metodologias e estratégias de ensino, sobretudo no que se refere ao ensino-aprendizado de Libras como segunda língua para/por alunos ouvintes (NOGUEIRA E CABELLO, 2017).

Nogueira e Cabello (2017) observaram uma lacuna em relação ao estudo dessa temática, e intencionalmente realizaram reflexões visando a contribuição para a área de metodologias e estratégias de ensino de língua de sinais, sobretudo no que se refere ao ensinoaprendizado de Libras como segunda língua para/por alunos ouvintes. A proposta de elaboração de narrativas audiovisuais pelos alunos participantes de cursos de Libras, fundamentada em uma abordagem de ensino de língua na perspectiva comunicativa, foi uma das atividades realizadas na experiência.

Desse modo, o uso de vídeo em situações de ensino de Libras para alunos ouvintes em uma abordagem comunicativa também já foi temática explorada no trabalho de Lebedeff e Santos (2014). A proposta de produção de vídeos das autoras pretendia distanciar-se de um ensino focado apenas nos elementos lexicais, mostrando-se válido, uma vez que, como as 


\title{
OFICINAS DE LIBRAS COMO L2 PARA ALUNOS OUVINTES
}

próprias autoras destacam, esse tipo de material pode ser aproveitado tanto no ensino de Libras presencial como a distância.

No entanto, enquanto essa experiência apresentou aos alunos materiais fílmicos prontos (elaborados por docentes), no trabalho desenvolvido pelas autoras são os próprios alunos que, por meio da produção dos materiais em vídeo, envolveram-se em práticas sociais de linguagem que ainda tiveram impacto nas representações (LEBEDEFF e SANTOS, 2014) sobre surdez, surdos e a Libras (NOGUEIRA E CABELLO, 2017).

O relato de experiência e as reflexões trazidas no artigo citado constituem-se como parte de um movimento das autoras que - por considerarem, assim como aponta Gesser (2012), que a prática profissional também é prática de construção de conhecimento por meio da qual o professor pensa e discute sobre seus próprios fazeres - buscaram refletir sobre os modos como organizaram/realizaram as estratégias pedagógicas para as disciplinas de Libras sob suas responsabilidades para fins de avaliação de suas práticas (NOGUEIRA E CABELLO, 2017).

Nesse movimento, portanto, pareceu relevante as autoras compartilhar a experiência com as narrativas audiovisuais, no intuito de que elas pudessem colaborar com o desenvolvimento de uma compreensão do que significa ensinar Libras como L2.

Segundo Nogueira e Cabello (2017).

\begin{abstract}
Consideramos que a análise das três narrativas em vídeo apresentada neste artigo corrobora a escolha pela abordagem comunicativa para o ensino de Libras como L2, a partir da qual as situações didáticas foram pensadas de acordo com as funções que os alunos precisariam realizar na língua alvo, o que possibilitou a eles, em situações criadas no contexto de ensino e aprendizagem, o acesso aos conhecimentos específicos da língua, ao mesmo tempo em que fizeram o uso pragmático da mesma. Nesse processo, acreditamos na validade da proposta das narrativas audiovisuais como estratégia didática, por considerarmos serem uma alternativa às práticas usuais de uso descontextualizado da Libras em situações artificiais, como tratado por Albres (2012), ou de apresentação de sinais descontextualizados e "soltos", como evidenciado por Neves (2012). O recurso de elaboração de narrativas possibilitou o envolvimento dos alunos na construção textual em Libras, o que mobilizou os conhecimentos linguísticos, políticos e sociais desenvolvidos ao longo das aulas.
\end{abstract}

Nas narrativas as autoras observaram a presença de sentenças em que aspectos como a noção temporal (presente, passado, futuro), a iconicidade e a simultaneidade foram explorados pelos alunos, que, diante das situações a serem narradas, tiveram a oportunidade de lançar hipóteses a respeito de novos vocabulários e construção de enunciados para a produção de sentidos nos discursos em Libras. As produções audiovisuais possibilitaram, ainda, que a tridimensionalidade da Libras em sua modalidade visual-gestual fosse um elemento contemplado e amplamente discutido ao longo das aulas, e esse movimento 
colaborou também para que, através das próprias narrativas, alunos e docentes pudessem ir contrastando as especificidades da língua-alvo (Libras) e da primeira língua (Português).

Para além da contribuição desta atividade pedagógica para aquisição de aspectos linguísticos da Libras, as autoras destacaram o papel fundamental que a atividade narrativa teve na ressignificação de noções sobre a pessoa surda e sobre o estatuto linguístico das línguas de sinais, contribuindo para o trabalho social e político, que também deve ser considerado objetivo das disciplinas de Libras.

Ao finalizar, as autoras destacaram que, considerando as potencialidades dos recursos digitais para o desenvolvimento de propostas metodológicas para o ensino de Libras como L2, elas acreditam que, assim como a experiência relatada, outras práticas que lancem mão dos recursos digitais podem ser bem sucedidas (NOGUEIRA E CABELLO, 2017).

A esse respeito, consideraram que o artigo supracitado possa ter, futuramente, desdobramentos na busca por desenvolver narrativas de maneira coletiva e colaborativa, numa proposta que vai ao encontro do que Sevilla-Pávon e Maddalena (2015) denominaram de narrativas digitais: "breves filmes resultantes da prática de combinar múltiplos modos de tecnologia, como fotografias, texto, música, narração de voz e clips de vídeo para produzir uma narrativa" (SEVILLA-PAVÓN e MADDALENA, 2015).

Desse modo, além da apresentação da história em Libras, os alunos poderiam, de maneira colaborativa, agregar ao vídeo outros recursos, como imagens, texto escrito em português, sons, trechos de outros vídeos, enfim, demais recursos que considerassem pertinentes para compor, em grupo, uma única narrativa. Alinhadas a Sevilla-Pávon e Maddalena (2015), acredita-se que essa maneira de realizar o trabalho com as narrativas digitais e o uso do recurso de vídeo gravação ainda ofereceriam momentos mais descontraídos e mais propícios à aquisição de conteúdo (SEVILLA PÁVON e MADDALENA, 2015), o que acreditamos contribuir para a apropriação de uma nova língua (NOGUEIRA E CABELLO, 2017).

Nesse sentido, Pereira (2016), em seu artigo sobre oficinas de Libras, compreende que a sociedade deve ter formação para incluir, comunicar-se e interagir com os surdos. Criou-se então um projeto para proporcionar tal interação entre surdos e ouvintes mediada através da Libras.

A Oficina de Libras ocorre desde 2014 com turmas em diferentes níveis de aprendizagem da Libras, sendo estas: Nível I, Nível II, Interação em Libras (ofertada no $1^{\circ}$ semestre de 2016) e Sinalizando (ofertada no $2^{\circ}$ semestre de 2016), construindo assim, equidade e igualdade de oportunidades nos mais diversos ambientes entre a comunidade surda e ouvintes. $\mathrm{O}$ trabalho desenvolvido com essas turmas ocorre através da exposição prática da Libras, vídeos, aplicativos, dinâmicas, exercícios, atividades de expressão corporal e facial, teatrais, tradução e 


\section{OFICINAS DE LIBRAS COMO L2 PARA ALUNOS OUVINTES}

interpretação da Libras/Língua Portuguesa e Língua Portuguesa/Libras e interação com a comunidade surda, as quais levam o público-alvo ao aprendizado (PEREIRA, 2016).

Oportunizou-se com o projeto apresentado por Pereira (2016), o aprendizado da Libras, a interação dos ouvintes com a comunidade surda, valorizando a cultura, a educação e a interatividade que é primordial para garantir os direitos da comunidade surda brasileira.

\footnotetext{
Verificou-se que $94 \%$ dos participantes concordaram plenamente que o Projeto forneceu conhecimento suficiente sobre a Libras, mas necessitam continuar a formação e sugerem novas turmas com níveis avançados. Assim, o Projeto está atingindo os objetivos propostos com êxito, oportunizando o acesso a Libras para a construção de uma sociedade mais igualitária e de respeito ao próximo (PEREIRA 2016).
}

Desse modo, Pereira (2016) evidencia que a oficina de Libras segue as politicas públicas, oferecendo assim o ensino nos diferentes níveis construindo equidade de oportunidades em diversos ambientes, utilizando-se de diversos recursos e metodologias.

\section{CONCLUSÕES}

A partir da compreensão abordada pelos autores discorrido no texto foi possível chegarmos ao entendimento de que as possiblidades de inclusão através de oficinas de Libras como segunda língua (L2) para alunos ouvintes é imprescindível para constituição e desenvolvimento do aluno surdo.

Nesse sentido, podemos observar que existem possibilidades sim de inclusão através do ensino da Língua Brasileira de Sinais (Libras) nas escolas públicas, visto que quando tratamos de inclusão apenas pensamos nos alunos com deficiência, mas existe um mundo a ser acessado pelos ouvintes.

Os materiais didáticos são recursos que motivam e envolvem os estudantes com o processo de ensino e aprendizagem da segunda língua. Estes materiais devem estar em consonância (articulado) com o planejamento da aula, principalmente com os objetivos propostos, para que ele possa ser um facilitador da aprendizagem.

Nesse sentido, o mundo da pessoa com deficiência que neste caso nos referimos aos surdos, que tem uma cultura riquíssima e que necessita de acessibilidade. Devemos construir de mãos dadas uma ponte que promova cada vez mais a inclusão dos ouvintes na comunidade surda, quebrando assim as barreiras comunicacionais.

Desse modo, para ensinar Libras como L2 para alunos ouvintes é necessário conhecer o perfil do estudante, os estilos de aprendizagens e estabelecer quais estratégias de ensino serão adotados, para obter os resultados dos objetivos traçados. 
Ficou claro, que a educação pautada na inclusão deve ser entendida como o ato de acolher pessoas independentemente de sua cor, etnia, religião, condições físicas e/ou psicológicas, sem exceções, principalmente quando tratamos sobre a inclusão no âmbito educacional.

Em fim, a escola comum torna-se inclusiva quando acolhe as diferenças dos alunos mediante o processo educacional buscando dessa forma a participação efetiva, bem como, a evolução de todos os educandos, sempre inovando em suas práticas pedagógicas, entretanto sabemos que esta não é uma tarefa fácil, pois requer a adoção de medidas e novas práticas para então gerar mudanças que atravessarão os muros da escola

\section{REFERÊNCIAS}

ALBRES, N. A. Os Diferentes Caminhos para uma educação bilíngue (Libras/Português) na Região Sul do Brasil. Revista Interinstitucional Artes de Educar. Rio de Janeiro Disponivel em: https://www.e-publicacoes.uerj.br/index.php/riae/article/view/29809. Acesso em: 19/07/2020.

ALBRES, N. A. Ensino de Libras como segunda língua e as formas de registrar uma língua visuo-gestual: problematizando a questão. REVEL, v. 10, n. 19, 2012.

BARBOSA, Ana C. A. LACERDA Lúcia L. Parâmetros de ensino em língua Brasileira de sinais como L2. Indaial: UNIASSELVI, 2019.

BRASIL. Política Nacional de Educação Especial na Perspectiva da Educação Inclusiva. MEC/SEESP, $2008 . \quad$ Disponível em: <http://portal.mec.gov.br/arquivos/pdf/politicaeducespecial.pdf>. Acesso em: 10 set 2020.

Lei n. 10.436, de 24 de abril 2002. Dispõe sobre a língua brasileira de sinais Libras - e dá outras providências. Brasília: Presidência da República. Disponível em: <http://www.planalto.gov.br/ccivil_03/Leis/2002/L10436.htm>. Acesso em 05 set. 2020.

Decreto n. 5.626, de 22 de dezembro de 2005. Regulamenta a Lei n. 10.436, de 24 de abril de 2002. Dispõe sobre a Língua Brasileira de Sinais - LIBRAS. Brasília, 2005.

KLEIN, Madalena. A educação dos surdos no Rio Grande do Sul. In: LOPES, Maura Corcini et al. (orgs). A Educação dos Surdos no Rio Grande do Sul. Relatório de pesquisa. São Leopoldo: Universidade do Vale do Rio dos Sinos, 2009.

FRANCO, Adriana Marques dos Santos Laia; SCHUTZ, Gabriel Eduardo. Sistema educacional inclusivo constitucional e o atendimento educacional especializado. Saúde debate, Rio de Janeiro , v. 43, n. spe4, p. 244-255, 2019 . Available from $<$ http://www.scielo.br/scielo.php?script=sci_arttext\&pid=S0103-

$11042019000800244 \& \operatorname{lng}=$ en\&nrm=iso $>$. access on 15 Out. 2020.

GESSER, A. O ouvinte e a surdez: sobre ensinar e aprender a Libras. São Paulo: Parábola Editorial, 2012. 
LEBEDEFF, T. B; SANTOS, A. N. Objetos de aprendizagem para o ensino de línguas: vídeos de curta-metragem e o ensino de Libras. RBLA. Belo Horizonte, v. 14, n. 4, p. 1073-1094, 2014.

NEVES, S. L. G. Um estudo dos recursos didáticos nas aulas de Língua Brasileira de Sinais para ouvintes. Anais Congresso TILS, 2012.

Nogueira, Aryane; Cabello, Janaina. O trabalho com narrativas audiovisuais no ensino de Libras como L2 para ouvintes. Revista Leitura V.1 n 57 - jan/jun 2016. Disponivel em: https://seer.ufal.br/index.php/revistaleitura/article/viewFile/2650/2868. Acesso em: 15 de Out de 2020.

PEREIRA, Natalia Amarilho. Oficina de Libras. Bento Gonçalves/ RS. Disponivel em: https://eventos.ifrs.edu.br/index.php/Salao/SEMEX2016/paper/viewFile/860/355. Acesso em: 19/05/2020.

SEVILLA-PÁVON, A.; MADDALENA, T. L. Aprendizagem de línguas com narrativas digitais: uma experiência no ensino do inglês para fins específicos. Revista Lugares de Educação [RLE], Bananeiras - PB, v. 5, n. 11, p. 255-267, Ago.-Dez., 2015.

THOMA, Adriana da Silva. Educação Bilíngue para Surdos no contexto da Educação Inclusiva. In: MORAES, Salete Campos de (org.). Educação inclusiva: diferentes significados. Porto Alegre - RS: Editora Evangraf, 2011. 